1 Running head: Enhancing arthropod diversity on grassland

2 \section{(1)}

\title{
Effects of ecological compensation meadows on arthropod diversity in adjacent
}

\section{intensively managed grassland}

Matthias Albrecht ${ }^{\mathrm{a}, 1, *}$, Bernhard Schmid ${ }^{\mathrm{b}}$, Martin K. Obrist ${ }^{\mathrm{a}}$, Beatrice Schüpbach ${ }^{\mathrm{c}}$, David Kleijn $^{\mathrm{d}, 2}$, and Peter Duelli ${ }^{\mathrm{a}}$

${ }^{a}$ Swiss Federal Institute for Forest, Snow and Landscape Research,

Zurcherstrasse 111, 8903 Birmensdorf, Switzerland

${ }^{\mathrm{b}}$ Institute of Environmental Sciences, University of Zurich,

Winterthurerstrasse 190, 8057 Zurich, Switzerland

${ }^{\mathrm{c}}$ Research station Agroscope Reckenholz-Tanikon ART,

Reckenholzlstrasse 1918046 Zurich, Switzerland

${ }^{\mathrm{d}}$ Nature Conservation and Plant Ecology Group, Wageningen University,

Bornsesteeg 69, 6708 PD Wageningen, The Netherlands

${ }^{*}$ Corresponding author. Tel.: +41 44635 6129; fax: +41 446355711

E-mail addresses: matthias.albrecht@uwinst.uzh.ch (M. Albrecht),

peter.duelli@wsl.ch (P. Duelli), martin.obrist@wsl.ch (M.K. Obrist),
David.Kleijn@,wur.nl (D. Kleijn), bschmid@uwinst.uzh.ch (B. Schmid)

${ }^{1}$ Present address: Institute of Environmental Sciences, University of Zurich,

3 Winterthurerstrasse 190, 8057 Zurich, Switzerland

${ }^{2}$ Present address: Centre for Ecosystem Studies, Alterra

P.O. Box 47, 6700 AA Wageningen, The Netherlands

This document is the accepted manuscript version of the following article: Albrecht, M., Schmid, B., Obrist, M. K., Schüpbach, B., Kleijn, D., \& Due11i, P. (2010). Effects of ecological compensation meadows on arthropod diversity in adjacent intensively managed grassland. Biological

Conservation, 143(3), 642-649. https://doi.org/10.1016/j.biocon.2009.11.029 


\section{Abstract}

An important goal of ecological compensation areas (ECAs) is to increase biodiversity in adjacent intensively managed farmland and the agricultural landscape at large. We tested whether this goal can be achieved in the case of the agrienvironmental restoration scheme implemented for Swiss grassland using five large arthropod taxa (bees, true bugs, orthopterans, ground beetles and spiders) representing different ecological and functional groups. The species richness and abundance of all groups and species, respectively, was measured along $100 \mathrm{~m}$ transects from ECAmeadows into the adjacent intensively managed grassland at 24 sites. Species richness of all arthropod taxa except ground beetles, and the abundance of $63 \%$ of the 234 arthropod species sampled with at least five individuals were higher in ECA-meadows than in their surroundings, while the total abundance of spiders and ground beetles was higher in intensively managed meadows. The abundance of $8 \%$ of these species were only increased in the ECA-meadows themselves ("stenotopic" species) but $40 \%$ had increased abundance both in the ECA-meadows and the adjacent grassland, declining exponentially with increasing distance from ECA-meadows (“edge species"). The 90\%-decay distances for these edge species differed among taxonomic groups $(117 \pm 18 \mathrm{~m}$ for true bugs, $137 \pm 24 \mathrm{~m}$ for spiders, $152 \pm 34 \mathrm{~m}$ for bees, $167 \pm$ $5.7 \mathrm{~m}$ for orthopterans, $185 \pm 34 \mathrm{~m}$ for ground beetles; mean \pm 1 standard error) and independent of taxonomic group were larger for large-sized or predacious species than for small-sized or phytophagous species. Because the average distance between neighbouring ECA-meadows in Swiss grassland is only $73 \pm 4 \mathrm{~m}$, the current agrienvrionment scheme very likely enhances arthropod diversity and possibly associated ecosystem services in the Swiss agricultural landscape at large. 


\section{Key words}

Agri-environment schemes, arthropod diversity, body size, meadow restoration, positive edge effect, trophic guild

\section{Introduction}

Agricultural intensification and the concomitant fragmentation of semi-natural habitats have been widely recognized as a serious threat to biodiversity (Robinson and Sutherland, 2002; Benton et al., 2002). Agri-environment schemes aim at counteracting the adverse effects of modern agriculture on biodiversity and at improving the general status of the environment by providing financial incentives to farmers for ecologically enhancing their land (OECD, 2003). Currently, these schemes cover approximately $25 \%$ of the farmed land of the 15 older member states of the European Union (Kleijn et al., 2006) and cost yearly around $€ 2.2$ billion (OECD, 2003). Hence, agri-environment schemes are considered the most important policy instrument to preserve and restore biodiversity in European agricultural landscapes (Vickery et al., 2004; Kleijn et al., 2006). The most important measure of the Swiss agri-environment scheme is that at least $7 \%$ of the farmland must be managed as ecological compensation areas (ECAs). These include a wide range of specific biotopes such as wild-flower strips, orchards, hedges or extensively managed hay meadows. ECA-meadows constitute by far the most widespread ECA type in Switzerland, making up 87\% of the total ECA-area in 2007 (BLW 2008). The management prescriptions for ECA meadows (hereafter abbreviated with 'ECAs') include postponed mowing and prohibition of fertilizer application. The success of agri-environment schemes in conserving and restoring farmland biodiversity is difficult to assess because they are poorly monitored (Kleijn 
and Sutherland, 2003). Some schemes have found to deliver mixed biodiversity benefits (Kleijn and Sutherland, 2003; Kleijn et al., 2006), whereas others, such as the Swiss scheme, have been more effective in preserving biodiversity (Albrecht et al., 2007a). The presence of target species, effective prescriptions, and the size and spatial arrangement of areas under agri-environment schemes are crucial to produce benefits to biodiversity (Ovenden et al., 1998; Vickery et al., 2004; Kleijn et al., 2006; Pywell et al., 2006).

An important missing link in the assessment of the effectiveness of the mentioned schemes is how ECAs affect biodiversity in the surrounding intensively managed farmland. The distribution and abundance of populations and their biotic interactions often depend on processes that are not confined to local habitat patches (e.g. Tscharntke et al., 2005). The resource use of species in agroecosystems is not restricted to a single habitat, but most species depend on complementary habitat resources to successfully complete their life cycle (Duelli and Obrist, 2003; Tscharntke et al., 2005). Such movement and exchange between habitat patches may play a central role in shaping diversity patterns and community structure in the mosaic of areas under agri-environment schemes and the surrounding intensively managed farmland. These processes may have important implications for ecosystem functioning and services, for example by enhancing natural pest control (Altieri, 1994) or pollination (Kremen et al., 2002; Albrecht et al., 2007a). Moreover, ecological resilience and the sustainability of agroecosystems may depend on a broad spectrum of biodiversity including a high diversity of functional groups (Bengtsson et al., 2003; Balvanera et al., 2006).

The aim of this study is fourfold. First, we examine whether restored meadows managed according to the prescriptions of the Swiss agri-environment scheme (ECA- 
101

102

103

104 124 the Swiss lowlands, consisting of a small-scale mosaic of grasslands, arable fields and 125 forests. The sites were not or only slightly sloped and ranged from 385 to $710 \mathrm{~m}$

meadows) sustain more species and individuals of different functional groups of arthropods and plants than intensively managed grasslands. Second, we quantify the proportion of arthropod species exhibiting positive edge effects along gradients from restored into surrounding intensively managed grassland. Third, we estimate $90 \%$ decay distances radiating out from ECA-meadows for the investigated species groups and compare them with average distances between ECA-meadows in the Swiss agricultural landscape. Finally, we analyse the influence of body size and trophic level on these decay distances.

We measured species richness and abundance of plants and of five groups of arthropods, i.e. bees (Hymenoptera: Apoidea), true bugs (Heteroptera), orthopterans (Orthoptera), ground beetles (Coleoptera: Carabidae) and spiders (Araneae) along gradients from 24 ECA-meadows into adjacent intensively managed grassland.

Ground beetles, spiders and predacious bugs are important bio-control agents (Fauvel, 1999; Symondson et al., 2002) and bees represent the most important pollinator group in agroecosystems (Kremen et al., 2002). Thus, it can be expected that, by increasing their biodiversity, ecosystem services provided by the groups can also be enhanced.

\section{Material and methods}

\subsection{Study design and sampling protocol}

Bees, true bugs, orthopterans, ground beetles and spiders were sampled on 24 sites (18 in 2003 and 6 additional ones in 2004) from ECA-meadows and from adjacent intensively managed grassland. These sites were located in the Cantons of Zurich, Aargau, Lucerne and Basel Land and represented the typical agricultural landscape of for. The sites were not or only slightly sloped and ranged from 385 to $710 \mathrm{~m}$ 
126 above sea level. The average minimal distance between sites was $3.2 \pm 0.7 \mathrm{~km}$,

127 ranging from 1.2 to $13.7 \mathrm{~km}$. The selected ECA-meadows were identical to the

128 adjacent intensively managed grasslands in exposition and slope and had been under

129 the agri-environment scheme for at least 5 years. The average size of an ECA-

130 meadow was $0.86 \pm 0.13$ ha, ranging from 0.20 to 2.83 ha. The average

131 perimeter/area ratio of an ECA-meadow was $0.071 \pm 0.006$ (range: $0.028-0.118$ ).

132 No significant effect of ECA-meadow size or perimeter/area ratio on species richness

133 or abundance of arthropods was found (all $P>0.05$ ). In the year of the arthropod

134 sampling the selected ECA-meadows were cut $1.9 \pm 0.1$ times, whereas intensively

135 managed meadows were cut $4.2 \pm 0.2$ times. As prescribed by the Swiss agri-

136 environment scheme, all ECA-meadows were cut the first time after 15 June. The first

137 cut of the intensively managed meadows took mostly place in the first half of May. A

138 further ECA-meadow management prescription was that the application of any

139 fertilizer was prohibited. On the other hand, all intensively managed meadows were

140 fertilized by liquid manure. To avoid possible confounding effects from semi-natural

141 habitats, only sites without such structures within approximately $100 \mathrm{~m}$ were chosen.

142 Since semi-natural landscape elements could also have affected arthropod

143 communities in focal meadows at an even larger spatial scale, the percentage semi-

144 natural habitat was recorded within a perimeter with a radius of $750 \mathrm{~m}$ and its

145 influence tested on species richness and abundance of spiders, true bugs and

146 orthopterans. The average proportion of semi-natural habitat and the variation in this

147 proportion was low $(3.9 \pm 0.4 \%$, ranging from 1.6 to $7.9 \%)$. No significant effect of

148 the percentage semi-natural habitat on the species richness and abundance of the three

149 arthropod taxa was detected (all $P>0.05$; Grimm, 2005). 
Spiders and ground beetles were captured with pitfall traps (funnel traps;

151 upper diameter of the funnel: $15 \mathrm{~cm}$ ). This trap type is recommended due to its very

152 high trapping efficiency (Obrist and Duelli, 1996). At each site, always one funnel

153 trap was located in the ECA-meadow (at $10 \mathrm{~m}$ distance from the borderline between

154 the ECA-meadow and the adjacent intensively managed grassland) and at distances of

15525,50 and $100 \mathrm{~m}$ from the ECA-meadow in the adjacent intensively managed

156 grassland. In both years, the traps were emptied bi-weekly between the last week of

157 April and the last week of September. Pitfall traps measure activity-density of ground-

158 dwelling arthropods. For simplicity, here we use the term "abundance" when referring

159 to the number of individuals, irrespective of the sampling method.

160 Wild bees were sampled by transect surveys with a bioquip 7112NA student

161 net (diameter $40 \mathrm{~cm}$; BioQuip Products, Rancho Dominquez, CA). During 15 minutes

162 each bee that was observed on a 1-m wide transect parallel to the borderline between

163 the ECA-meadow and the adjacent intensively managed grassland was captured

164 (Banaszak, 1980; Kleijn et al., 2006; Knop et al., 2006). Bee transect surveys were

165 made at the same distances from the borderline between ECA-meadow and

166 intensively managed grassland as the pitfall samplings. Further arthropods, especially

167 orthopterans and true bugs, were sampled by using the same transect as for the bees

168 but sweeping a bioquip 7625HS heavy duty net 60 times over the ground within each

169 transect (general sweep netting). Sampling with these two methods was not done at

170 the same date to avoid interference among them. In both years, three survey rounds

171 were carried out with the bee transect and four with the general sweep netting method.

172 These surveys were done between May and September, on sunny days from 10 am to

$1734 \mathrm{pm}$. The sampled bees, orthopterans, bugs and spiders were sorted out for further

174 analysis. 
The cover of individual plant species and the total number of plant species

\subsection{Classification of arthropods}

Each arthropod specimen was identified to species level. Each species was assigned to ecological groups according to body size and trophic level. Species were classified into the four size classes "large", "medium", "small" and "very small" and the three trophic guilds "predators", "herbivores" and "omnivores". The classification of Apoidea, Araneae, Carabidae and Heteroptera is based on Schweiger et al. (2005). Body size and trophic level of species not assigned in Schweiger et al. (2005) were obtained from the literature (the authors will provide references on request).

\subsection{Data analysis}

To analyse variation in abundance and species richness of arthropod groups (both ecological and taxonomic groups) and species richness of plants, we fitted general linear models with site as blocking factor and distance as treatment factor (ECAmeadow, 25, 50 and $100 \mathrm{~m}$ ). The distance factor was decomposed into a management contrast (ECA-meadow vs. intensively managed grassland), a log-distance contrast (increasing distance within intensively managed grassland) and the remaining deviation from log-linearity (within intensively managed grassland). We used a logdistance contrast in all analyses, because it fitted the data better than a linear distance contrast (see Results section). The general linear model was fitted for each taxon, trophic level and size class separately using the pooled data of all survey rounds over 
both seasons. The covariate "plant species richness" was entered before the distance contrast into the statistical model.

In order to quantify the proportion of arthropod species in ECA-meadows and surrounding intensively managed grasslands contributing to a positive edge effect of ECA-meadows into adjacent intensively managed grasslands the following procedure was applied: first, we excluded all species with less than five recorded specimens from the dataset (45\% of the total number of arthropod species). For each of the remaining 234 species we fitted negative exponential functions $\left(y=e^{a-b \cdot \sqrt{D}}\right.$, where a and $\mathrm{b}$ are parameters and $\mathrm{D}$ is the distance from ECA-meadow) to the combined number of captured individuals of all sites. The exponential function fitted the data better than exponential power and Weibull functions (data not shown). To eliminate between-site variation, we normalized captures among sites (e.g. Cronin et al., 2000). We used PROC NLIN procedure provided by the SAS statistical software package (version 8.2, SAS Institute Inc., Cary, North Carolina) to estimate the parameters of the function.

Each species was assigned to one of the three distribution types "stenotopic" species, "edge" species or "other" species according to its distribution pattern along the sampled gradient (Duelli and Obrist, 2003). Species only occurring in the meadow were classified as stenotopic species for ECAs. A few species occurred with at least 20 individuals in the ECA-meadows and negligible abundance in the intensively managed grasslands ( $\geq 20$ times lower abundance in intensively managed grasslands than in ECA-meadows). These species were also attributed to the distribution type "stenotopic species". Of the remaining species, those exhibiting a significant fit to the negative exponential function $(P \leq 0.05)$ were classified as edge species. The remaining species were classified as other species (i.e. "ubiquistic" 
species occurring at similar densities in the two habitat types and species occurring at higher densities in intensively managed habitat; since we were mainly interested in the effects of ECA-meadows as source habitats supplying nearby intensively managed grassland habitat and for the sake of simplicity we did not separate the latter two species groups).

231 ECA-meadows into intensively managed grasslands is difficult to measure accurately

232 due to the exponential nature of such effects (e.g. Hylander, 2005). Following 233 Hylander (2005), 90\%-decay distances were estimated as the distance where the 234 abundance declined to $10 \%$ of that found in the ECA-meadow. Decay distances were 235 only estimated for edge species. A general linear model was used to analyse the 236 effects of taxon, trophic level and body size on 90\%-decay distances. As only two 237 edge species were omnivorous, only herbivores and predators were included in this 238 analysis.

Log-linear models and analysis of deviance were used to explore the effects of 240 trophic guild and body size on the distribution type of species (Crawley, 2005).

241 Distribution type was decomposed into the contrasts edge species vs. rest (contrast 1)

242 and stenotopic species vs. other species within rest (contrast 2). To test the

243 relationship between these contrasts and body size or trophic level we fitted the 244 interaction between the contrasts and the trait factors.

245 To compare the $90 \%$-decay distances of different arthropod groups with the 246 average minimum distance between ECA-meadows in the Swiss lowland agricultural 247 landscape, the distance between 522 ECA-meadows and their nearest neighbouring 248 ECA-meadow was calculated. A total of 56 municipalities distributed all over the 249 Swiss lowlands were selected by a stratified random sampling (see Herzog et al., 
2005). The ECA-meadows were mapped during the years 1999 and 2000, digitised and analysed by means of a geographical information system (subsequent versions of ArcInfo). For the analysis of average ECA-meadow distances, those within a $200 \mathrm{~m}$ buffer of the municipalities' borders were excluded, thus avoiding possible bias introduced by ECA-meadows located peripherally at municipality boundaries. This restriction reduced the number of municipalities to 26 . The mean distance between nearest neighbour ECA-meadows in the Swiss lowlands was $72.6 \pm 4.0 \mathrm{~m}$. performed in R (R Development Core Team 2008). Abundances of all arthropod groups were square-root transformed to achieve normality and homoscedasticity

260 (Crawley, 2005). Unless otherwise stated, arithmetic means \pm 1 standard error are 261 reported.

\section{Results}

\section{3.1. Taxonomic groups}

265 A total of 144,630 arthropod individuals belonging to 423 species were sampled. Of

266 these, 234 species were represented by at least five specimens (Table 1). Total 267 arthropod species richness and the abundance of $63 \%$ of the 234 arthropod species 268 sampled with at least five individuals were higher in ECA-meadows than in adjacent 269 intensively managed grasslands (Table 2, Fig.1). Similarly, species richness and 270 abundance of true bugs, bees and orthopterans and species richness of spiders was 271 higher in restored than in intensively managed grasslands (Table 2, Fig. 1). In 272 contrast, the abundance of the two taxa with most individuals sampled, spiders and 273 ground beetles, and thus also total arthropod abundance, was higher in intensively 274 managed grasslands than in ECA-meadows (Table 2, Fig. 1). Species richness and 
abundance of bees and true bugs, species richness of ground beetles and total species richness of all arthropods declined with increasing distance from ECA-meadows (Table 2, Fig. 1). Of the species sampled with at least five specimens $8 \%$ were restricted to ECA-meadows ("stenotopic" species) whereas $40 \%$ were "edge" species, exponentially declining with increasing distance from ECA-meadows.

Plant species richness was significantly higher in ECA-meadows than in intensively managed grasslands $\left(F_{1,23}=446.70, P<0.001\right)$, but did not decline with increasing distance from ECA-meadows $\left(F_{1,23}=1.24, P=0.278\right)$ (Fig. 2). Plant species richness was positively related to the number of species and abundance of bees (ANCOVA: $\left.F_{1,22}=9.32, P=0.006 ; F_{1,22}=14.16, P=0.001\right)$ and the species richness of true bugs $\left(F_{1,22}=4.98, P=0.036\right)$, but was negatively correlated with spider abundance $\left(F_{1,22}=7.40, P=0.013\right)$.

\subsection{Ecological groups}

Species richness and abundance of phytophagous and omnivorous arthropods was higher in ECA-meadows than in intensively managed grasslands, while predator abundance showed the opposite pattern (Table 2, Fig. 3). Species richness of all three trophic guilds and the abundance of phytophagous arthropods declined with distance from ECA-meadows (Table 2, Fig. 3). Species richness of small-sized $\left(F_{1,23}=99.51\right.$, $P<0.001)$, medium-sized $\left(F_{1,23}=160.57, P<0.001\right)$ and large-sized arthropods $\left(F_{1,23}\right.$ $=101.35, P<0.001)$, and the abundance of very small $\left(F_{1,23}=25.70, P<0.001\right)$ and small arthropods $\left(F_{1,23}=58.50, P<0.001\right)$ was higher in ECA-meadows than in adjacent intensively managed grasslands. Furthermore, the species richness $\left(F_{1,23}=\right.$ 20.83, $P<0.001)$ and abundance $\left(F_{1,23}=18.44, P<0.001\right)$ of small-sized and the species richness of medium-sized $\left(F_{1,23}=19.31, P<0.001\right)$ and marginally 
significantly also that of large-sized arthropods $\left(F_{1,23}=3.08, P=0.093\right)$ decreased with increasing distance from ECA-meadows.

Edge species included more phytophagous and less predacious species than expected $\left(G^{2}=12.76, d f=1, P \leq 0.001\right)$ and were larger $\left(G^{2}=5.78, d f=1, P=0.017\right)$ than stenotopic and other species (Table 1). Furthermore, stenotopic species included less predacious and more other species than expected $\left(G^{2}=12.68, d f=1, P \leq 0.001\right)$. Both body size and trophic level significantly affected 90\%-decay distances of species: large and predacious species showed larger decay distances than small and phytophagous species (Table 3,4). While the taxonomic identity per se had no significant effect on decay distance, the interaction of taxonomic group with body size was significant, indicating a taxon-specific effect of body size (Table 4).

\section{Discussion}

\subsection{Increased plant and arthropod diversity in ECA-meadows}

Grassland restoration according to the prescriptions of the Swiss agri-environment scheme significantly enhanced species richness of all arthropod taxa (except ground beetles) and plants. Sixtythree per cent of the 234 arthropod species sampled with at least five specimens occurred in higher densities in restored grassland than in adjacent intensively managed grassland. These percentages are probably conservative estimates, because due to the higher number of sampling points the probability of detecting a very rare species in intensively managed grasslands was higher than detecting such a species in ECA-meadows. Our findings corroborate recent research documenting enhanced species richness of plants, bees, hover flies and orthopterans in ECA-meadows compared with intensively managed grasslands in Switzerland (Herzog et al., 2005; Knop et al., 2006; Albrecht et al., 2007a, 2007b). Plant species 
richness in agricultural meadows has been found to be negatively correlated with both intensity of fertilizer and mowing intensity (Zechmeister et al., 2003). A wide range of plant species cannot effectively use increased nitrogen inputs and are generally outcompeted by the few species that can use increased nitrogen levels for increased biomass production, a process that has recently been suggested to be driven mainly by competition for light (Hautier et al., 2009). Early and frequent mowing strongly increases the competitive dominance of fast growing species and may prevent late flowering species from pollination and seed production (Jantunen et al., 2007). The higher arthropod species richness in ECA-meadows might be explained by a bottomup effect of plant species richness on primary consumer diversity, which in turn may have facilitated the observed increase in spider species richness at the third trophic level (Siemann, 1998; Balvanera et al., 2006). The increased species richness and abundance of bees in ECA-meadows compared with intensively managed meadows was probably primarily a consequence of the higher and more continuous floral resource availability in ECA-meadows, i.e. an increased flower abundance and species richness of flowering plants (Pywell et al., 2006; Albrecht et al, 2007a). Better nesting opportunities for ground-nesting bees may also have played a role (Potts et al., 2005). Our results are in a line with those of studies on the effects of mowing regime on single arthropod taxa, suggesting that earlier and more frequent cutting of meadows affect true bug (Di Giulio et al., 2001), orthopteran (Guido and Gianelle, 2001) and spider diversity (Baines et al., 1998) more negatively than ground beetle diversity (Morris, 2000; Humbert et al., 2009). Hay harvesting can affect arthropods in at least three ways: i) direct mortality during the harvest process, ii) changes in the physical structure of the swards, which is associated with changes microclimatic conditions, iii) movements out of short cut swards due to a lack of resources and 
increased predation risk or movements into mown fields (see 4.2) (Guido and

351 Gianelle, 2001; Haysom et al., 2004; Humbert et al., 2009).

352 As predicted by resource concentration hypothesis (Root, 1973) several studies have

353 found higher abundances of arthropod taxa at higher fertilization levels of grasslands,

354 as plant productivity increases, and as plant composition shifts to a few dominant

355 plant species with high tissue quality (Strong et al., 1984; Siemann, 1998; Haddad et

356 al., 2000). In a line with these studies, the abundance of the two taxa sampled with

357 highest numbers of individuals, spiders and ground beetles, and thus also total total

358 abundance, was higher in the intensively managed grasslands than in the ECA-

359 meadows, but not that of bees, true bugs or orthopterans. This suggests that also prey

360 abundance of spiders and ground beetles, mostly generalist predators, was higher in

361 intensively managed meadows. It is also conceivable that the vegetation structure of

362 the intensively managed meadows is more favourable to cursorial movement of the

363 ground dwelling spiders and ground beetles (Symondson et al., 2002). In contrast, the

364 higher abundances of the generally more specialized true bugs and orthopterans in

365 ECA-meadows are probably primarily a consequence of the increased plant diversity 366 and the lower mowing frequency in these meadows.

\subsection{Influence of ECA-meadows on surrounding intensively managed grasslands}

369 We could detect positive edge effects from restored into adjacent intensively managed 370 grassland in a large number of arthropod species (94 out of 234 species sampled with 371 at least five specimens). The typical exponential decline with increasing distance from 372 ECA-meadow was not due to a decline in plant diversity, which was constantly low

373 across the intensively managed grasslands. This suggests that the management regime 374 in these meadows was probably too intensive and competition with species well 
adapted to such conditions too strong for a detectable?? successful colonization of new plant species from ECA-meadows. Increased abundance and diversity of arthropods in the proximity of these ECA-meadows may positively affect the level of ecosystem functions and services in intensively managed grasslands (Albrecht et al., 2007a).

We suggest that the following three potentially interrelated processes most likely caused the abundance and diversity gradients from restored into intensively managed grasslands: i) passive dispersal of arthropods reproducing or overwintering in ECA-meadows into intensively managed grasslands, ii) foraging from restored into intensively managed grasslands of arthropods reproducing or overwintering in ECAmeadows and iii) refuge seeking of arthropods foraging and reproducing mainly in intensively managed grassland into ECA-meadow habitat (Ries et al., 2004; Rand et al., 2006). Extensively managed meadows may generally be more favourable sites for reproduction and overwintering for grassland arthropods compared to intensively managed grasslands due to lower disturbance levels for reproduction and larval development and potentially better conditions for overwintering (Haysom et al., 2004). Nevertheless, intensively managed grasslands can provide ephemeral high quality resources for generalist arthropods (Symondson et al., 2002; Rand et al., 2006). Therefore, it is possible that many of the species identified as edge species, occurring at higher densities in ECA-meadows when looking at the entire season, have benefited from the transiently increased resource base provided by adjacent intensively managed grasslands (ii). However, it is also conceivable that transient concentration effects in ECA-meadows, caused by disturbances such as mowing or fertilizer application in intensively managed grasslands forcing surviving arthropods to search refuges in nearby ECA-meadows (iii), partly contributed to the observed 
edge effects. Edge effects from intensively managed grassland into ECA-meadows

401 were not investigated in this study, which is an interesting research area for future

402 studies.

4.3. Decay distances of species radiating out from ECA-meadows into intensively managed grasslands

406 The spatial extent of edge effects is difficult to measure accurately, because of the 407 exponential nature of most edge effects (e.g. Hylander, 2005). Because exponential 408 functions never decay completely and are difficult to estimate at the tail (Kot et al., 409 1996), we used the distance at which the decay reached $90 \%$ (10\% remaining) as a measure (Hylander, 2005). The estimated 90\%-decay distances for most species were

411 only slightly larger than the measured distance range from 0-100 $\mathrm{m}$ and can therefore 412 be considered as minimal extrapolations.

413 Considering the dense network of ECA-meadows in the investigated

414 landscapes of the Swiss lowlands dominated by grasslands, with an average distance

415 of only $73 \mathrm{~m}$ between neighbouring ECA-meadows, these 90\%-decay distances 416 indicate that most of the surrounding matrix of intensively managed grasslands can be 417 reached by the investigated arthropod species. Thus, our findings suggest that in 418 regions where ECA-meadows are the prevailing type of ECAs the ECA-meadow419 network may successfully increase arthropod diversity in the agricultural landscape at 420 large.

\subsection{Ecological groups}

423 The large number of arthropod taxa investigated allowed us to analyse differences in

424 edge effects among ecological groups of trophic guild and body size. We found 
pronounced differences in the proportion of species showing edge effects among trophic guilds. About half of the investigated phytophagous species showed positive edge effects, whereas this proportion was approximately a third for predacious species. Predacious arthropods appeared to be much more ubiquistic, with about two thirds of all investigated species showing similar or even higher abundances in intensively managed grasslands compared to phytophagous species, of which a considerable percentage was stenotopic for ECA-meadows (14\%) and less than $40 \%$ were ubiquistic. Among the edge species, phytophagous species had shorter $90 \%$ decay distances than predacious species. These findings suggest that proximity to restored areas is an important factor shaping the community and trophic structure of the investigated grasslands. These ecological traits explained more variation in decay distances among species than did taxonomic traits. This supports suggestions of a recent study (Schweiger et al., 2005) that local arthropod communities in agricultural landscapes may primarily be structured by differences in body size and trophic guild. The observed positive relationship between body size and decay distance is predicted by allometric scaling laws (Peters, 1986; Woodward et al., 2005). However, a positive scaling holds only for active movement (Peters, 1986; Etienne and Olff, 2004). If movement is predominantly passive, very small species are expected to exhibit larger movement distances (Etienne and Olff, 2004). From the sampled arthropod taxa in our study, such passive dispersal by wind is known for very small, primarily linyphid spiders ("ballooning”) (Marc et al., 1999). Indeed, 90\%-decay distances for species of this very small size guild were larger than for small size guilds of other arthropods.

\section{Conclusions and implications}


Studies on habitat fragmentation report edged effects on arthropod communities within habitat fragments (e.g. Laurance et al., 2002). In the context of ECAs, edge

451 effects around ECAs may be desirable, because they can enhance arthropod diversity 452 in surrounding habitat, as shown here for a large number of species covering a broad 453 taxonomic and ecological spectrum. Our findings indicate that the different taxa and 454 ecological groups differ considerably in the proportion of species and the spatial 455 extent to which they show edge effects. From a conservation biological point of view, 456 the enhanced species richness and abundance of arthropods in ECA-meadows and 457 their surroundings is not only valuable in itself but has also the potential to promote 458 ecosystem functions and services such as pollination and pest control in the 459 intensively managed adjacent grassland and in the agricultural landscape at large, 460 because distances between ECA-meadows in Switzerland are short. Our results have 461 general implications for the planning of the spatial configuration of restored and 462 protected areas in intensively managed landscapes, emphasizing that biodiversity and 463 potentially associated ecosystem services are not confined to such habitats, but 464 emanate to various extents into the surrounding intensively managed habitat, 465 contingent on the ecological traits of a species. Our findings underline the critical role 466 of a well connected network of ECAs in promoting biodiversity in the agricultural 467 landscape at large. We recommend that farmers should be encouraged to participate in 468 schemes that aim to enhance connectivity between ECAs.

\section{Acknowledgements}

471 We are grateful to Oliver Schweiger and co-workers, who kindly provided their data 472 concerning species' body size class and trophic guild. We thank Gwendoline Altherr 473 and Ilona Grimm for performing the vegetation surveys and Peter Wirz for assistance 
in the field. We thank the following taxonomic specialists for species identification: Anne-Catherine Grandchamp (ground beetles), Ralf Peter Heckmann (true bugs), Xaver Heer (spiders), Yvonne Schwarzenbach and Katrin Hartmann (orthopterans) and Sabine Oertli for checking the bee identifications. We are also grateful to Christine B. Muller for valuable comments on an earlier version of the paper. The study was carried out as part of the European research project "Evaluating current European agri-environment schemes to quantify and improve nature conservation efforts in agricultural landscapes" (EASY). The project was funded by the European commission (QLRT-2001-01495) and the Swiss Federal Office for Science and Technology (01.0524-2).

\section{References}

Albrecht, M., Duelli, P., Muller, C., Kleijn, D., Schmid, B., 2007a. The Swiss agrienvironment scheme enhances pollinator diversity and plant reproductive success in nearby intensively managed farmland. Journal of Applied Ecology 44, 813-822.

Albrecht, M., Duelli, P., Schmid, B., Muller, C.B., 2007b. Interaction diversity within quantified insect food webs in restored and adjacent intensively managed meadows. Journal of Animal Ecology 76, 1015-1025.

Altieri, M.A., 1994. Biodiversity and pest management in agroecosystems. Haworth Press, New York.

Baines, M., Hambler, C., Johnson, P.J., MacDonald, D.W., Smith, H., 1998. The effects of arable field margin management on the abundance and species richness of Araneae (spiders). Ecography 21, 74-86. 
Balvanera, P., Pfisterer, A.B., Buchmann, N., He, J.S., Nakashizuka, T., Raffaelli, D., Schmid, B., 2006. Quantifying the evidence for biodiversity effects on ecosystem functioning and services. Ecology Letters 9, 1146-1156.

Banaszak, J., 1980. Studies and methods of censusin the number of bees (Hymenoptera, Apoidea). Polish Ecological Studies 6, 355-366.

Bengtsson, J., Angelstam, P., Elmqvist, T., Emanuelsson, U., Folke, C., Ihse, M., Moberg, F., Nystrom, M., 2003. Reserves, resilience and dynamic landscapes. Ambio 32, 389-396.

Benton, T.G., Bryant, D.M., Cole, L., Crick, H.Q.P., 2002. Linking agricultural practice to insect and bird populations: a historical study over three decades. Journal of Applied Ecology 39, 673-687.

BLW, 2008. Agrarbericht. Swiss Federal Office for Agriculture, Bern.

Crawley, M.J., 2005. Statistics: An Introduction Using R. Wiley, Chichester, UK.

Cronin, J.T., Reeve, J.D., Wilkens, R., Turchin, P., 2000. The pattern and range of movement of a checkered beetle predator relative to its bark beetle prey. Oikos 90 , $127-138$

Di Giulio, M., Edwards, P.J., Meister, E., 2001. Enhancing insect diversity in agricultural grasslands: the roles of management and landscape structure. Journal of Applied Ecology 38, 310-319.

Duelli, P., Obrist, M.K., 2003. Regional biodiversity in an agricultural landscape: the contribution of seminatural habitat islands. Basic And Applied Ecology 4, 129138.

Etienne, R.S., Olff, H., 2004. How dispersal limitation shapes species-body size distributions in local communities. American Naturalist 163, 69-83. 
521 Fauvel, G., 1999. Diversity of Heteroptera in agroecosystems: role of sustainability and bioindication. Agriculture Ecosystems \& Environment 74, 275-303.

523 Guido, M., Gianelle, D., 2001. Distribution patterns of four Orthoptera species in relation to microhabitat heterogeneity in an ecotonal area. Acta Oecologica 22, 175-185.

Grimm, I., 2005. Wie beeinflussen die Landschaftsdiversität und naturnahe Nutzungstypen die Arthropodenvielfalt auf Extensiv- und Intensivwiesen? Diploma thesis. Swiss Federal Institute for Forest, Snow and Landscape Research, Birmensdorf.

Haddad, N.M., Haarstad, J., Tilman, D. 2000. The effects of long-term nitrogen loading on grassland insect communities. Oecologia 124, 73-84.

Hautier, Y., Niklaus, P.A., Hector, A. 2009. Competition for light causes plant biodiversity loss after eutrophication. Science 324, 636-638.

Haysom, K.A., McCracken, D.I., Foster, G.N., Sotherton, N.W., 2004. Developing grassland conservation headlands: response of carabid assemblage to different cutting regimes in a silage field edge. Agriculture Ecosystems \& Environment $102,263-277$.

Herzog, F., Dreier, S., Hofer, G., Marfurt, C., Schupbach, B., Spiess, M., Walter, T., 2005. Effect of ecological compensation areas on floristic and breeding bird diversity in Swiss agricultural landscapes. Agriculture Ecosystems \& Environment 108, 189-204.

Humbert, J.Y., Ghazoul, J., Walter, T., 2009. Meadow harvesting techniques and their impacts on field fauna. Agriculture, Ecosystems and Environment 130, 1-8.

Hylander, K., 2005. Aspect modifies the magnitude of edge effects on bryophyte growth in boreal forests. Journal of Applied Ecology 42, 518-525. 
Jantunen, J., Saarinen, K., Valtonen, A., Saarnio, S. 2007. Flowering and seed production success along roads with different mowing regimes. Applied Vegetation Science 10, 285-292.

Kleijn, D., Baquero, R.A., Clough, Y., Diaz, M., De Esteban, J., Fernandez, F., Gabriel, D., Herzog, F., Holzschuh, A., Johl, R., Knop, E., Kruess, A., Marshall, E.J.P., Steffan-Dewenter, I., Tscharntke, T., Verhulst, J., West, T.M., Yela, J.L., 2006. Mixed biodiversity benefits of agri-environment schemes in five European countries. Ecology Letters 9, 243-254.

Kleijn, D., Sutherland, W.J., 2003. How effective are European agri-environment schemes in conserving and promoting biodiversity? Journal of Applied Ecology 40, 947-969.

Knop, E., Kleijn, D., Herzog, F. \& Schmid, B., 2006. Effectivness of the Swiss agrienvironment scheme to promote biodiversity. Journal of Applied Ecology 43, $120-127$.

Kot, M., Lewis, M.A., van den Driessche, P., 1996. Dispersal data and the spread of invading organisms. Ecology 77, 2027-2042.

Kremen, C., Williams, N.M., Thorp, R.W., 2002. Crop pollination from native bees at risk from agricultural intensification. Proceedings of the National Academy of Sciences of the United States of America 99, 16812-16816.

Laurance, W.F., Lovejoy, T.E., Vasconcelos, H.L., Bruna, E.M., Didham, R.K., Stouffer, P.C., Gascon, C., Bierregaard, R.O., Laurance, S.G., Sampaio, E., 2002. Ecosystem decay of Amazonian forest fragments: A 22-year investigation. Conservation Biology 16, 605-618.

Marc, P., Canard, A., Ysnel, F., 1999. Spiders (Araneae) useful for pest limitation and bioindication. Agriculture Ecosystems \& Environment 74, 229-273. 
Morris, M.G., 2000. The effects of structure and its dynamics on the ecology and conservation of arthropods in British grasslands. Biological conservation 95, 129142.

Obrist, M.K., Duelli, P., 1996. Trapping efficiency of funnel- and cup-traps for epigeal arthropods. Mitteilungen der Schweizerischen Entomologischen Gesellschaft 69, 361-369.

OECD, 2003. Agricultural policies in OECD countries: monitoring and evaluation. Organisation for Economic Co-operation and Development, Paris.

Ovenden, G.N., Swash, A.R.H., Smallshire, D., 1998. Agri-environment schemes and their contribution to the conservation of biodiversity in England. Journal of Applied Ecology 35, 955-960.

Peters, R.H., 1986. The ecological implications of body size. Cambrigde University Press, Cambridge.

Potts, S.G., Vulliamy, B., Roberts, S., O'Toole, C., Dafni, A., Ne'Eman, G., Willmer, P., 2005. Role of nesting resources in organising diverse bee communities in a Mediterranean landscape. Ecological Entomology 30, 78-85.

Pywell, R.F., Warman, E.A., Hulmes, L., Hulmes, S., Nuttall, P., Sparks, T.H., Critchley, C.N.R., Sherwood, A., 2006. Effectiveness of new agri-environment schemes in providing foraging resources for bumblebees in intensively farmed landscapes. Biological Conservation 129, 192-206.

Rand, T.A., Tylianakis, J.M., Tscharntke, T., 2006. Spillover edge effects: the dispersal of agriculturally subsidized insect natural enemies into adjacent natural habitats. Ecology Letters 9, 603-614. 
Ries, L., Fletcher, R.J., Battin, J., Sisk, T.D., 2004. Ecological responses to habitat edges: Mechanisms, models, and variability explained. Annual Review of Ecology Evolution and Systematics 35, 491-522.

Robinson, R.A., Sutherland, W.J., 2002. Post-war changes in arable farming and biodiversity in Great Britain. Journal of Applied Ecology 39, 157-176.

Root, R.B., 1973. Organization of a plant-arthropod association in simple and diverse habitats: the fauna of collards (Brassica oleraceae). Ecological Monographs 43, 95-124.

Schweiger, O., Maelfait, J.P., Van Wingerden, W., Hendrickx, F., Billeter, R., Speelmans, M., Augenstein, I., Aukema, B., Aviron, S., Bailey, D., Bukacek, R., Burel, F., Diekotter, T., Dirksen, J., Frenzel, M., Herzog, F., Liira, J., Roubalova, M., Bugter, R., 2005. Quantifying the impact of environmental factors on arthropod communities in agricultural landscapes across organizational levels and spatial scales. Journal of Applied Ecology 42, 1129-1139.

Siemann, E., 1998. Experimental tests of effects of plant productivity and diversity on grassland arthropod diversity. Ecology 79, 2057-2070.

Strong, D.R. Jr., Lawton, J.H., Southwood, T.R.E., 1984. Insects on plants: community patterns and mechanisms. Harvard University Press, Cambridge.

Symondson, W.O.C., Sunderland, K.D., Greenstone, M.H., 2002. Can generalist predators be effective biocontrol agents? Annual Review of Entomology 47, 561594.

Tscharntke, T., Klein, A.M., Kruess, A., Steffan-Dewenter, I., Thies, C., 2005.

16 Landscape perspectives on agricultural intensification and biodiversity 617 ecosystem service management. Ecology Letters 8, 857-874. 
618 Vickery, J.A., Bradbury, R.B., Henderson, I.G., Eaton, M.A., Grice, P.V., 2004. The

619 role of agri-environment schemes and farm management practices in reversing the

620 decline of farmland birds in England. Biological Conservation 119, 19-39.

621 Woodward, G., Ebenman, B., Ernmerson, M., Montoya, J.M., Olesen, J.M., Valido, 622 A., Warren, P.H., 2005. Body size in ecological networks. Trends In Ecology \& 623 Evolution 20, 402-409.

624 Zechmeister, H.G., Schmitzberger, I., Steurer, B., Peterseil, J., Wrbka, T., 2003. The 625 influence of land-use practices and economics on plant species richness in 626 meadows. Biological Conservation 114, 165-177. 
627 Table 1. Numbers of arthropod species and individuals sampled in ECA-meadows

628 and at distances of 25, 50 and $100 \mathrm{~m}$ from the ECA-meadows within adjacent

629 intensively managed grasslands $(n=24)$. Species sampled with at least five specimens

630 were assigned to three distribution types according to their spatial patterning along the

631 transects: stenotopic species for ECA-meadows, edge species exponentially declining

632 with increasing distance from ECA-meadows and other species

\begin{tabular}{|c|c|c|c|c|c|c|c|c|}
\hline \multirow{2}{*}{\multicolumn{2}{|c|}{ Group }} & \multicolumn{2}{|c|}{ Number of } & \multicolumn{2}{|c|}{ Number of species } & \multicolumn{3}{|c|}{ Distribution type } \\
\hline & & Total & Nind $^{3} 5$ & Total & Nind $^{3} 5$ & $\begin{array}{c}\text { Stenotopic } \\
\text { species (\%) }\end{array}$ & $\begin{array}{c}\text { Edge species } \\
(\%)\end{array}$ & $\begin{array}{c}\text { Other species } \\
(\%)\end{array}$ \\
\hline \multicolumn{9}{|c|}{ Taxonomic } \\
\hline & Araneae & 58.066 & 57.944 & 144 & 68 & 4 & 38 & 58 \\
\hline & Gnaphosidae & 348 & 345 & 9 & 6 & 0 & 100 & 0 \\
\hline & Linyphiidae & 15.929 & 15.892 & 46 & 23 & 9 & 13 & 78 \\
\hline & Lycosidae & 36.647 & 36.643 & 20 & 18 & 0 & 39 & 61 \\
\hline & Theridiidae & 186 & 173 & 10 & 4 & 0 & 25 & 75 \\
\hline & Thomisidae & 569 & 560 & 13 & 5 & 0 & 80 & 20 \\
\hline & Other families & 4.387 & 4.331 & & & & & \\
\hline & Coleoptera (Carabidae) & 54.011 & 53.955 & 102 & 70 & 1 & 30 & 69 \\
\hline & Heteroptera & 13.058 & 12.989 & 94 & 57 & 14 & 49 & 26 \\
\hline & Anthocoridae & 306 & 302 & 7 & 4 & 0 & 0 & 100 \\
\hline & Lygaeidae & 372 & 350 & 17 & 7 & 43 & 29 & 29 \\
\hline & Miridae & 9.944 & 9.926 & 31 & 22 & 14 & 55 & 32 \\
\hline & Pentatomidae & 575 & 567 & 12 & 7 & 14 & 86 & 0 \\
\hline & Tingidae & 823 & 823 & 5 & 5 & 60 & 40 & 0 \\
\hline & Other families & 1.038 & 1.021 & & & & & \\
\hline & Hymenoptera (Apoidea) & 4272 & 4194 & 69 & 28 & 0 & 50 & 50 \\
\hline & Orthoptera & 15.223 & 15.219 & 14 & 11 & 9 & 46 & 46 \\
\hline & Acrididae & 14.293 & 15.293 & 7 & 7 & 14 & 43 & 43 \\
\hline & Other families & 930 & 926 & & & & & \\
\hline \multicolumn{9}{|c|}{ Trophic } \\
\hline & Phytophagous & 36.123 & 35.976 & 181 & 104 & 14 & 49 & 38 \\
\hline & Predacious & 105.531 & 105.357 & 229 & 123 & 3 & 33 & 63 \\
\hline & Omnivorous & 2.976 & 2.968 & 13 & 7 & 14 & 29 & 57 \\
\hline \multicolumn{9}{|c|}{ Body size } \\
\hline & Large & 8.677 & 8.627 & 57 & 32 & 9 & 47 & 44 \\
\hline & Medium & 53.412 & 53.348 & 99 & 59 & 5 & 61 & 34 \\
\hline & Small & 24.359 & 24.241 & 120 & 65 & 11 & 35 & 54 \\
\hline & Very small & 58.182 & 58.085 & 147 & 78 & 8 & 26 & 67 \\
\hline Total & & 144.63 & 144.301 & 423 & 234 & 8 & 40 & 52 \\
\hline
\end{tabular}


634 Table 2. Summary of ANOVAs testing the effects of management and distance from

635 ECA-meadow on species richness and abundance of five arthopod taxa (pooled data

636 of 24 transects). Management was tested as a contrast ECA-meadow vs. intensively

637 managed grassland, and distance from ECA-meadow as a contrast log-distance from

638 ECA-meadow within intensively managed grassland. Abundances of all arthropod

639 taxa were square-root transformed. Values in italics indicate effects in opposite

640 direction to the hypothesis, i.e. ECA-meadows < intensively managed grasslands.

641

\begin{tabular}{|c|c|c|c|c|c|}
\hline \multirow[b]{2}{*}{ Arthropod taxa } & \multirow[b]{2}{*}{ Df } & \multicolumn{2}{|c|}{ Management } & \multicolumn{2}{|c|}{ Log-distance } \\
\hline & & $F$ & $P$ & $F$ & $P$ \\
\hline \multicolumn{6}{|l|}{ Number of species } \\
\hline Spiders & 1,23 & 39.76 & $<0.001$ & 0.71 & 0.408 \\
\hline Ground beetles & 1,23 & 0.49 & 0.492 & 6.84 & 0.015 \\
\hline True bugs & 1,23 & 309.33 & $<0.001$ & 14.3 & 0.001 \\
\hline Bees & 1,23 & 103.58 & $<0.001$ & 8.42 & 0.008 \\
\hline Orthopterans & 1,23 & 10.92 & 0.003 & 2.25 & 0.158 \\
\hline Phytophagous & 1,23 & 454.37 & $<0.001$ & 28.59 & $<0.001$ \\
\hline Predacious & 1,23 & 0.01 & 0.921 & 6.55 & 0.018 \\
\hline Omnivorous & 1,23 & 5.01 & 0.035 & 19.22 & $<\mathbf{0 . 0 0 1}$ \\
\hline Total & 1,23 & 150.26 & $<0.001$ & 16.13 & 0.001 \\
\hline \multicolumn{6}{|l|}{ Number of individuals } \\
\hline Spiders & 1,23 & 13.54 & 0.001 & 0.06 & 0.815 \\
\hline Ground beetles & 1,23 & 22.35 & $<0.001$ & 0.87 & 0.361 \\
\hline True bugs & 1,23 & 211.99 & $<0.001$ & 21.02 & $<0.001$ \\
\hline Bees & 1,23 & 112.5 & $<0.001$ & 13.38 & 0.001 \\
\hline Orthopterans & 1,23 & 74.38 & $<0.001$ & 0.15 & 0.707 \\
\hline Phytophagous & 1,23 & 271.61 & $<0.001$ & 13.03 & 0.002 \\
\hline Predacious & 1,23 & 46.84 & $<0.001$ & 0.27 & 0.609 \\
\hline Omnivorous & 1,23 & 26.54 & $<0.001$ & 0.1 & 0.754 \\
\hline Total & 1,23 & 7.32 & 0.013 & 0.01 & 0.922 \\
\hline
\end{tabular}


643 Table 3. Estimation of the 90\%-decay distance (mean \pm 1 standard error) radiating

644 out from ECA-meadows into intensively managed grasslands for five arthropod taxa,

645 two trophic guilds and four size classes. For the calculation of the $90 \%$-decay distance

646 see Methods section. Included are only species with a significant $(P \leq 0.05)$ decline

647 with distance from ECA-meadows into intensively managed grasslands, i.e. species

648 classified as edge species.

\begin{tabular}{cc}
\hline Group & $\begin{array}{c}90 \% \text {-decay } \\
\text { distance }\end{array}$ \\
\hline
\end{tabular}

Taxonomic

$\begin{array}{ll}\text { Araneae } & 137( \pm 24) \\ \text { Carabidae } & 185( \pm 34) \\ \text { Heteroptera } & 117( \pm 18) \\ \text { Apoidea } & 152( \pm 34) \\ \text { Orthoptera } & 167( \pm 57)\end{array}$

Trophic
Phytophagous
$125( \pm 15)$
Predacious
$171( \pm 22)$

Body size

$\begin{array}{ll}\text { Large } & 176( \pm 39) \\ \text { Medium } & 145( \pm 21) \\ \text { Small } & 130( \pm 22) \\ \text { Very small } & 141( \pm 25)\end{array}$


650 Table 4. Results of ANOVA testing the effects of taxonomic status, trophic position

651 and body size on 90\%-decay distances radiating out from ECA-meadows into

652 intensively managed grasslands. The five taxonomic groups are bees, true bugs,

653 orthopterans, ground beetles and spiders. The two trophic guilds are herbivores and

654 predators. For the calculation of the $90 \%$-decay distance see Methods section.

655 Included are only species with a significant $(P \leq 0.05)$ decline with distance from

656 ECA-meadows into intensively managed grasslands, i.e. species classified as "edge

657 species".

658

\begin{tabular}{lrrr}
\hline Source & Df & $F$ & $P$ \\
\hline Taxonomic group & 4 & 1.42 & 0.235 \\
Trophic guild & 1 & 8.27 & $\mathbf{0 . 0 0 5}$ \\
Body size & 1 & 5.09 & $\mathbf{0 . 0 2 7}$ \\
Taxonomic group x trophic guild & 1 & 3.16 & 0.079 \\
Taxonomic group x body size & 4 & 2.82 & $\mathbf{0 . 0 3 1}$ \\
Trophic guild x body size & 1 & 0 & 0.985 \\
Taxonomic group x trophic guild x body size & 1 & 0.06 & 0.81 \\
Error & 75 & & \\
\hline
\end{tabular}


660

661

662

663

664

665

666

667

668

669

670

671

672

673

674 Fig. 3. Mean number ( \pm 1 standard error) of (a) individuals and (b) species of

675

676

677

678

679 shown.

Figure legends

Fig. 1. Mean number ( \pm 1 standard error) of (a) individuals and (b) species of bees, true bugs, orthopterans, ground beetles, spiders and all arthropod taxa combined in ECA-meadows $(0 \mathrm{~m})$ and at distances of 25, 50 and $100 \mathrm{~m}$ from the ECA-meadows within intensively managed grasslands. For better visualisation, abundance of Apoidea was multiplied by five at each distance. Untransformed, pooled data of 24 transects are shown.

Fig. 2. Mean number ( \pm 1 standard error) of vascular plant species in ECA-meadows $(0 \mathrm{~m})$ and at distances of 25, 50 and $100 \mathrm{~m}$ from the ECA-meadows within intensively managed grasslands. Untransformed, pooled data from five $2 \times 5 \mathrm{~m}$ plots at each distance class of 24 transects are shown.

predators, pollinators and herbivores in ECA-meadows $(0 \mathrm{~m})$ and at distances of 25, 50 and $100 \mathrm{~m}$ from the ECA-meadows within intensively managed grasslands. For better visualisation, pollinator abundance was multiplied by 50 and pollinator species 
682

683

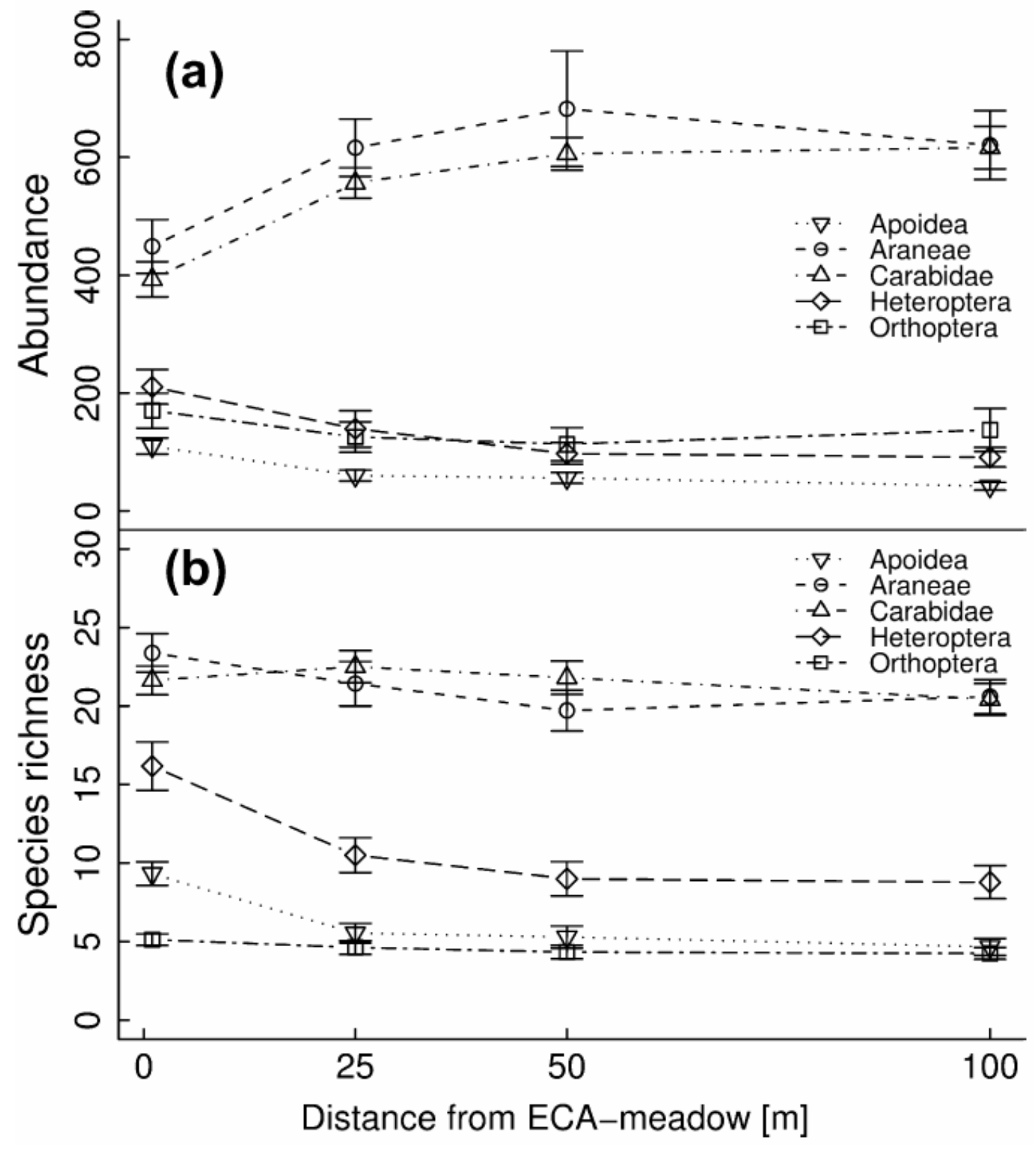

Fig. 1 
685

686

Fig. 2

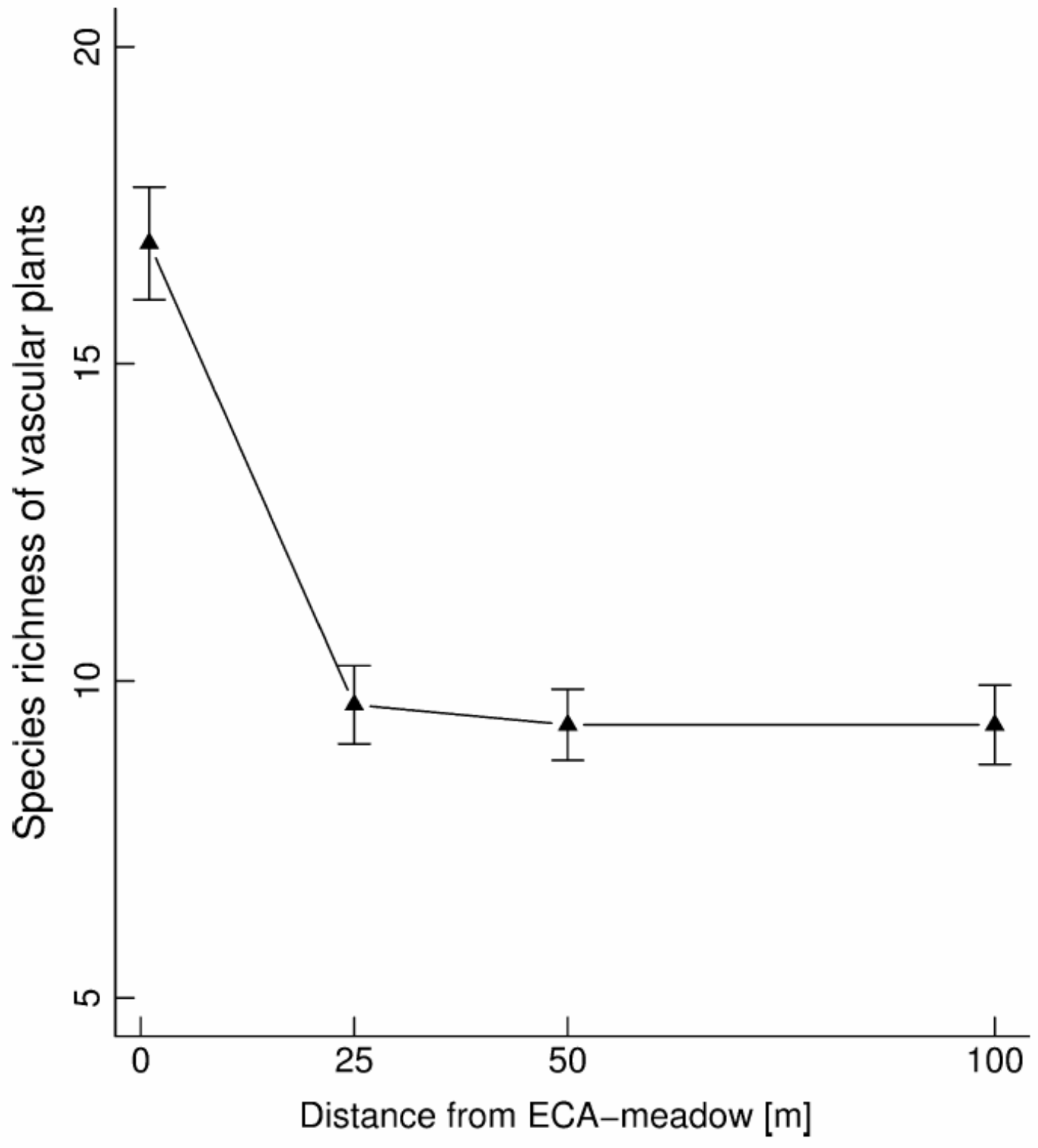


Fig. 3

689

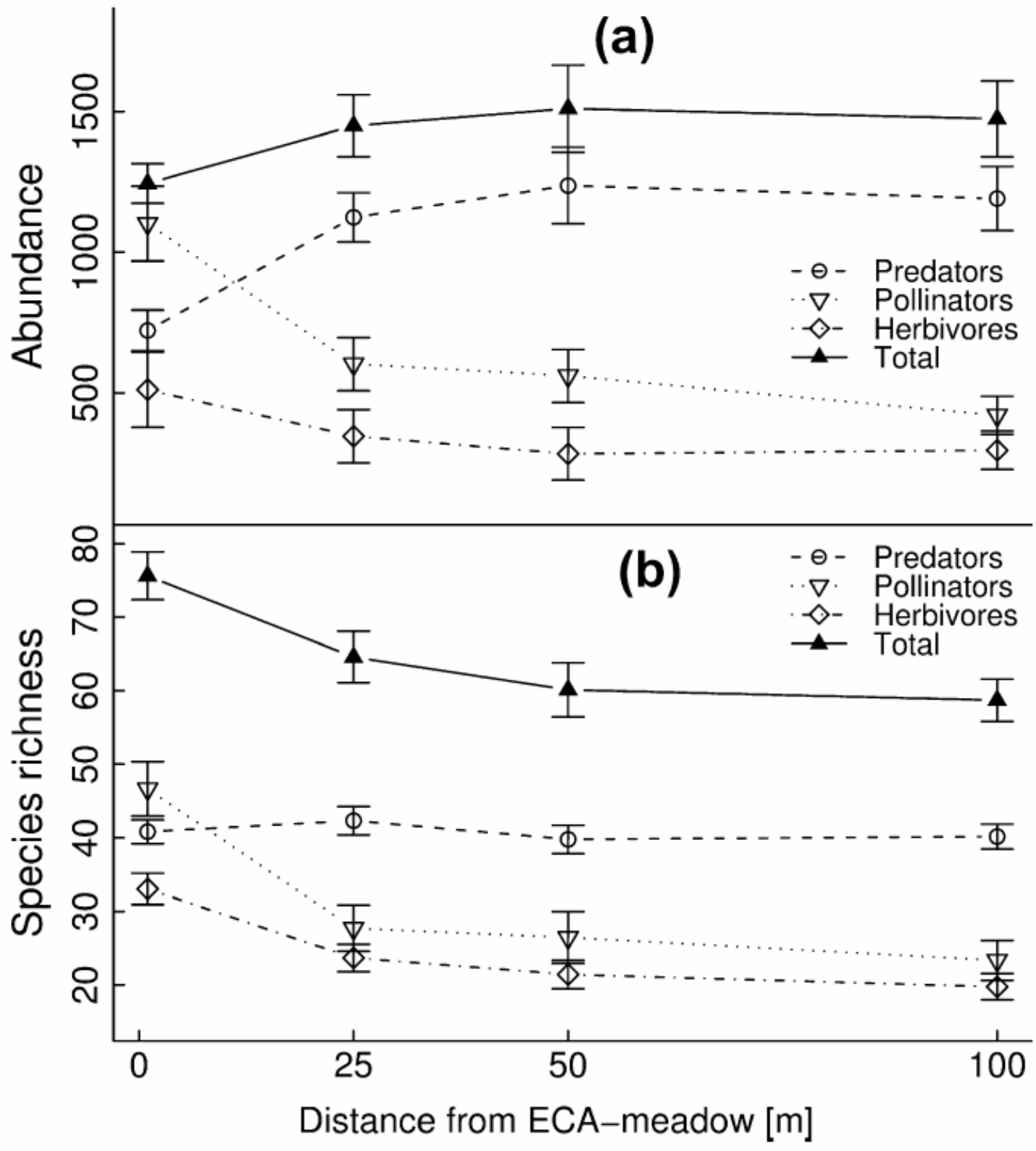

